\title{
Genetic diversity of Taraxacum officinale Wigg. local populations in the habitats of Nizhniy Tagil different in the level of technogenic load
}

\author{
E. Artemenko*, E. Zhuikova, I. Kiseleva \\ Ural Federal University, Yekaterinburg, Russia \\ *e-mail: lisaaartemenko@gmail.com
}

Key words: Taraxacum officinale, genetic diversity, ISSR-analisis

Motivation and Aim: Industrial pollutants are strong stressorsthat can cause degradation of genetic system in population [1]. The aim is to study the level of genetic diversity of local populations of Taraxacum officinale growing in the locations of Nizhny Tagil, differed in the level of technogenic impact.

Methods and Algorithms: NA was isolated by the method of S. Porebski [2] with some modifications. Eight UBC primers was used for PCR. Visualization of PCR results was carried out by horizontal electrophoresis on a $1.2 \%$ agarose gel in addition of ethidium bromide in $1 \times$ TBE buffer. The results of all electrophoregrams were processed by the ImageJ program. The presence and absence matrices for each primer were processed in PAST [3] and JeneAlex [4] programs.

Results: In our study, 92 samples of $T$. officinale were analyzed; standardization of the ISSR protocol, quantitative and qualitative assessments of the NA were done; the maximum, minimum and average number of bands per sample, habitat and primer, as well as indicators of genetic diversity: the percentage of polymorphic loci, effective alleles, expected heterozygosity, the Shannon`s information index, the genetic distance and identity of Nei, the percentage of molecular variance within and among populations . Conclusion: The genetic analysis of five subpopulations of T. officinale revealed that there are no statisticallysignificant differences between these subpopulations. This indicates that in T. officinale species, adaptability to heavy metals in the environment is manifested probably by physiological level - acclimation, which does not change the genetic structure of populations.

\section{References}

1. Makhnev A.K. (2010) Problems of selection and conservation of forest genetic reserves in the areas of location of large industrial centers in the Urals. Coniferous boreal zone. (1-2):127-130 (in Russian).

2. Porebski S., Bailey L.G., Baum B.R. (1997) Modification of a CTAB DNA extraction protocol for plants containing high polysaccharides and polyphenol component. Plant Molecular Biology Reporter. 15:8-15.

3. Hammer Ø., Harper D.A.T., Ryan P.D. (2001) PAST: Paleontological statistics software package for education and data analysis. Palaeontologia Electronica. 4(1):9.

4. Peakall R., Smouse P.E. (2012) GenAlEx 6.5: genetic analysis in Excel. Population genetic software for teaching and research-an update. Bioinformatics 28:2537-2539. 